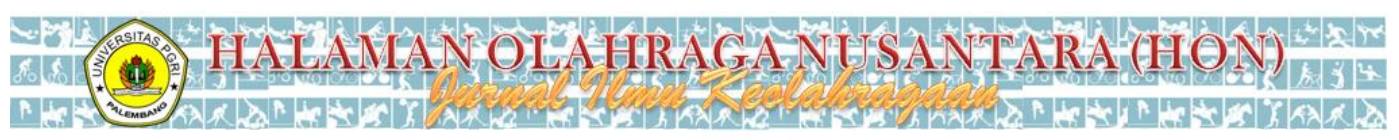

Volume 4 No 1

ISSN 2614-2775 (Print)

Tahun 2021

ISSN 2621-8143 (Online)

\title{
TABATA WORKOUT DALAM MENINGKATKAN KEBUGARAN ATLET PANAHAN
}

\author{
Arisman $^{1}$, Tiara Noviarini ${ }^{2}$ \\ ${ }^{1,2}$ Universitas Mitra Karya, Indonesia. \\ arisman.900225@gmail.com, tiaranoviarini140315@gmail.com
}

\begin{abstract}
Abtrak
Tujuan penelitian ini ialah mengetahui kebugaran Atlet UKM Panahan dan juga sebagai variasi yang dapat digunakan dalam latihan. Variasi latihan tersebut yaitu latihan Tabata. Penelitian ini menggunakan jenis eksperimen dengan sampel berjumlah 25 responden. Teknik penarikan sampel memakai Purposive Sampling dan pengumpulan datanya menggunakan TKJI. Analisis data yang sudah dilakukan menunjukan terdapatnya pengaruh latihan tabata terhadap peningkatan kebugaran atlet UKM Panahan. Dengan hasil perhitungan $\mathrm{t}_{\text {-hitung }}$ lebih besar dari $\mathrm{t}_{\text {-tabel }}$ atau $\mathrm{t}$-hitung $(4,25)>\mathrm{t}_{\text {-tabel }}(1,711)$. Hasil Tes Awal Kebugaran sebelum diberikan treatment Latihan Tabata ditemukan yang memiliki kebugaran dengan rentangan 5-9 Kasifikasi Kurang Sekali (KS) sebanyak 0 dengan Persentase (0\%) skor 10-13 berada pada klasifikasi Kurang (K) sebanyak 14 responden dengan Persentase (56\%) dan skor 14-17 berada pada klasifikasi Sedang (S) sebanyak 8 responden dengan Persentase (32\%), kemudian skor 18-21 berada pada klasifikasi Baik (B) sebanyak 3 responden dengan Persentase (12\%), selanjutnya rentangan skor 22-25 pada klasifikasi baik sekali (BS) sebanyak 0 dengan Persentase (0\%). Sedangkan Hasil Tes Akhir kebugaran setelah diberikan perlakuan latihan tabata ditemukan yang memiliki kebugaran dengan rentangan skor 5-9 Kasifikasi Kurang Sekali (KS) sebanyak 0 dengan Persentase (0\%) skor 10-13 berada pada klasifikasi Kurang (K) sebanyak 2 responden dengan Persentase (8\%) dan skor 14-17 berada pada klasifikasi Sedang (S) sebanyak 8 responden dengan Persentase (32\%), kemudian skor 18-21 berada pada klasifikasi Baik (B) sebanyak 12 responden dengan Persentase (48\%), kemudian skor 22-25 pada klasifikasi baik sekali (BS) sebanyak 3 responden dengan Persentase (12\%).
\end{abstract}

Kata kunci: Latihan Tabata, Kebugaran Fisik

\section{TABATA WORKOUT IN IMPROVING THE FITNESS OF THE ARCHATHLETE}

\begin{abstract}
This study aims to identify the fitness of Archery's UKM and also as variations that can be used in training. The variation of the exercise is the exercise of Tabata. The type of research used in this study is an experiment with a total of 25 respondents. Sample withdrawal technique uses a purposive sampling and data collection using TKJI. Data analysis shows how Tabata exercises affect the fitness of the Archery's UKM. With a higher t-count than t-table or t-count (4.25) > t-table (1,711). Initial fitness test results before treatment with tabata training are found that have a fitness with a 5-9 Poor classification $(P)$ by a percentage of $(0 \%)$, score of 10-13 is on Less than Satisfactory classification (LS) by 14 respondents with a percentage (56\%) and score of $14-17$ is on

Correspondence author: arisman, universitas mitra karya, indonesia. E-Mail: arisman.900225@gmail.com (c) (i) (2)

Jurnal Halaman Olahraga Nusantara licensed under a Creative Commons Attribution-ShareAlike 4.0 International License.
\end{abstract}


Satisfactory classification (S) by 8 of the respondents with a percentage (32\%), then score of 18 to 21 is on a Good classification $(G)$ by 3 respondents with a percentage $(12 \%)$, then score of 22-25 on Excellent $(E)$ as many as 0 with a percentage (0\%). Whereas the results of the final fitness test after Tabata training are found that have significantly improved with a 5-9 Poor classification $(P)$ with a percentage (0\%). Score of 10-13 is on classification of Less than Satisfactory $(L S)$ as many as 2 respondents with a percentage (8\%) and score of 14-17 is on Satisfactory $(S)$ as many as 8 respondents with a percentage (32\%), then score of 18 to 21 is on a Good classification $(G)$ as many as 12 respondents with a percentage (48\%), Then score of 22-25 is on an Excellent classification (E) as many as 3 respondents with a percentage (12\%).

Keywords: Tabata Workout, Physical Fitness

\section{PENDAHULUAN}

Aktifitas olahraga yang menggunakan busur dan menembakkan anak panah ke sebuah target disebut dengan Olahraga panahan. Ini dijadikan bukti sejarah bahwasanya panahan sudah ada semenjak lima ribu tahun silam yang awal mulanya digunakan untuk berburu dihutan dan seiring perkembangan zaman dijadikan sebagai senjata dalam suatu pertempuran lama kelamaan berubah menjadi olahraga ketepatan. Orang yang gemar olahraga ini merupakan orang yang ahli dalam memanah sering disebut sebagai pemanah.

“Olahraga Panahan sangat Baik sekali untuk dilakukan karena panahan salah satu olahraga yang sangat baik untuk melatih fokus dan berkonsentrasi dalam semua aspek. Olahraga ini juga direkomendasikan oleh Nabi Muhammad SAW begitu juga dengan Olahraga Berkuda dan Berenang" (ARISMAN \& Okilanda, 2020)

Panahan merupakan Olahraga yang membutuhkan kebugaran fisik sebab dilakukan dalam jangka waktu yang lama. Peran Kebugaran fisik disini sangat berkontribusi dalam mencapai suatu prestasi yang diinginkan. Kebugaran memiliki klasifikasi tertinggi sebab orang yang bugar menggambarkan sudah memiliki kesehatan individu yang baik, orang yang sehat belum tentu bugar dalam melakukan kegiatan sehari-hari.

Kebugaran merupakan aspek fisik yang berkontribusi secara keseluruhan dalam tubuh untuk memberikan kemampuan individu dalam menjalani kehidupan secara produktif serta penyesuaian diri dalam menerima beban pada fisik secara baik. 
"Kebugaran jasmani diartikan sebagai kesanggupan dalam aktifitas seharihari sehingga bisa beradaptasi terhadap pembebanan fisik tanpa menimbulkan keletihan secara berlebih serta masih mempunyai energi cadangan untuk menikmati waktu senggang maupun pekerjaan yang mendadak serta terhindar dari penyakit” (Devy Amelia Nurul Alamsyah*,Retno Hestiningsih, 2017) selanjutnya "Kondisi tubuh seseorang memiliki peranan penting dalam melakukan aktivitas sehari-hari untuk mencapai kebugaran jasmani. Setiap individu perlu memiliki tingkat kebugaran secara ideal untuk disesuaikan dengan kegiatan sehari-hari dalam menjalani kehidupan" (Arifin, 2018).

Secara umum kebugaran dikategorikan sebagai klasifikasi energi yang tinggi agar sanggup melakukan kegiatan sehari-hari dan tidak merasakan kelelahan karena adanya cadangan energi di dalam tubuh yang dimanfaatkan secara pas dan teratur.

\section{Komponen Kebugaran}

Komponen ini sangat penting diketahui karena merupakan faktor penentu hasil kebugaran seseorang. (Giri Wiarto 2015) menyatakan bahwa kebugaran dan kesehatan saling berkaitan dan juga memiliki komponen dasar, seperti:

“1) Kekuatan sebagai kemampuan otot dalam tubuh untuk memikul beban atau melakukan aktivitas. 2) Daya Tahan digunakan untuk kesanggupan individu dalam menjalankan organ dalam tubuh, misalnya paru, jantung, dan organ lainnya secara efisien sekaligus efektif. 3) Kekuatan Otot untuk kemampuan dalam menghasilkan kekuatan secara penuh secara cepat. 4) Kecepatan digunakan untuk mengukur kemampuan otot dalam waktu gerakan sesingkat mungkin. 5) Kelentukan sebagai kemampuan dalam menggerakkan tubuh secara luwes. 6) Kelincahan merupakan kemampuan cepat dan bervariasi pada otot tubuh dalam melakukan gerakan, misalnya gerakan berpindah dari kanan ke kiri, dari depan ke belakang. 7) Koordinasi sebagai kemampuan tubuh dalam menghubungkan berbagai macam gerakan cepat secara efektif. 8) Keseimbangan sebagai kemampuan tubuh dalam mengawasi sistem organ tubuh dan syaraf sehinggap bisa mengontrol tubuh secara baik. 9) Ketepatan adalah kemampuan tubuh sebagai pengendali gerak dalam membidik target dengan tepat. 10) Reaksi sebagai rangsangan stimulus terhadap suatu obyek". 
Kesemua komponen fisik tersebut bisa dilakukan agar kebugaran yang diinginkan bisa tercapai dengan baik, salah satunya dengan menerapkan latihan Tabata. Latihan ini merupakan latihan interval yang dilakukan secara intens untuk meningkatkan detak jantung dalam waktu singkat. Tabata juga termasuk kedalam High Intensity Interval Training. Latihan ini pada umumnya sebagai latihan dayatahan dan latihan kekuatan yang digabungkan. Latihan ini dibuat berdasarkan metode interval waktu dengan sistem yang mudah, misalnya melakukan Olahraga selama 20 detik dengan intensitas tinggi kemudian diberi istirahat selama 10 detik, diulangi beberapa set sampai latihan dilakukan selama 4 menit. Waktu istirahat yang pendek ini bertujuan untuk memaksa tubuh untuk terus bergerak sebelum pulih dari set sebelumnya. Latihan ini mampu membakar banyak kalori karena seluruh gerakannya tidak hanya memompa kerja jantung dan paru melainkan juga melatih berbagai otot tubuh.

Olahraga memiliki peranan penting terhadap pencapaian kondisi tubuh yang sehat karena olahraga merupakan kegiatan yang baik dilakukan untuk mencapai kebugaran apabila dilakukan secara terarah, tepat dan teratur serta lama kelamaan menjadi terbiasa dan terlatih. Era teknologi saat ini membuat sebagian orang enggan melakukan olahraga karena faktor kesibukan pekerjaan dan lainnya sehingga aktifitas gerak fisik sangat kurang efeknya resiko berbagai penyakit akan mudah menyerang. Olahraga bisa dijadikan sebagai alternatif untuk menangani hal tersebut.

\section{METODE}

Penelitian ini menggunakan metode kuantitatif dengan jenis eksperimen. Adapun langkah yang dilakukan yaitu (pretest-treatment-posttest) untuk melihat peningkatannya. Atlet UKM panahan UMIKA sebagai populasi yang berjumlah 38 Orang. Menurut (Sugiono, 2010) "Populasi ialah keseluruhan obyek atau subyek dengan karakteristik dan kualitas tertentu yang ditetapkan oleh peneliti dan ditarik kesimpulannya". Lebih lanjut (Arikunto, 2006) menuturkan bahwasanya "populasi merupakan keseluruhan subjek penelitian". 
Sampel diambil dengan cara teknik Purposive Sampling yaitu berdasarkan suatu pertimbangan untuk dijadikan sampel. Adapun sampel yang dimaksud ialah seluruh Atlet Putra berjumlah 25 Orang. Lebih jelasnya bisa dilihat pada tabel berikut:

Tabel 1. Sampel Penelitian

\begin{tabular}{cccc}
\hline No & Putra & Putri & Jumlah \\
\hline $\mathbf{1}$ & 25 Orang & 13 Orang & 38 Orang \\
\hline
\end{tabular}

(Sumber : UKM Panahan Umika)

(Sugiyono, 2010) menyatakan bahwa "pola eksperimen yang digunakan dalam penelitian ini adalah one-group pretest-test design. Alasan pemilihan pola eksperimen ini karena terdapat pre test, treatment dan post test didalamnya serta sangat erat kaitan nya dengan masalah yang di teliti”.

\section{Teknik Pengumpulan Data}

Data dikumpulkan menggunakan TKJI (Tes Kesegaran Jasmani Indonesia) Dalam pelaksanaannya tediri 5 butir tes yang dilaksanakan secara berurutan. Butir tes tersebut dapat dijabarkan sebagai berikut:

Tabel 2. Butir Tes TKJI Sesuai Kelompok Umur

\begin{tabular}{cccc}
\hline & \multirow{2}{*}{ Butir Tes } & \multicolumn{2}{c}{$16 \mathrm{~s} / \mathrm{d} 19 \mathrm{Th}$} \\
\cline { 2 - 4 } & Lari Cepat Sprint & $60 \mathrm{~m}$ & $60 \mathrm{~m}$ \\
\hline 1 & Gantung Siku Tekuk & - & $\checkmark$ \\
\hline 2 & Gantung Angkat Tubuh & $\checkmark$ & - \\
\hline 3 & Baring Duduk & 60 & 60 \\
\hline 4 & Loncat Tegak & $\checkmark$ & $\checkmark$ \\
\hline 5 & Lari Jarak Menengah & $1200 \mathrm{~m}$ & $1000 \mathrm{~m}$ \\
\hline \multicolumn{4}{c}{ (Arsil, 2015) }
\end{tabular}

Tabel 3. Norma TKJI

\begin{tabular}{ccc}
\hline No & -Jumlah Nilai- & -Klasifikasi Kesegaran Jasmani- \\
\hline 1 & $22-25$ & Baik Sekali (BS) \\
\hline 2 & $18-21$ & Baik (B) \\
\hline 3 & $14-17$ & Sedang (S) \\
\hline 4 & $10-13$ & Kurang (K) \\
\hline 5 & $5-9$ & Kurang Sekali (KS) \\
\hline
\end{tabular}

(Arsil, 2015) 


\section{OLAHA $\overline{\text { HAGA }}$}

JURAL HAII KOOL NUSANTARA

Jendral A. Yani Street Lorong Gotong Royong 9/10 Ulu

\section{Analisis Data}

Data hasil tes awal dan tes akhir selanjutnya dilakukan analisis menggunakan rumus statistik dengan mengikuti langkah perhitungan, antara lain :

1) Uji normalitas, untuk mengetahui data berdistribusi normal atau tidaknya menggunakan rumus Lilliefors.

2) Uji homogenitas varians, untuk mengetahui data tergolong sama atau berbeda.

3) Selanjutnya uji hipotesis.

Uji-t dilakukan untuk mengetahui perbedaan dari treatment yang dilakukan dengan rumus :

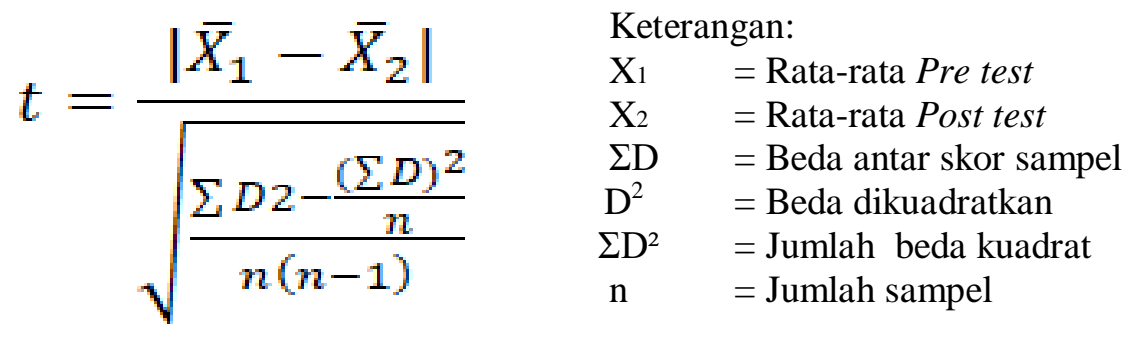

(Hasan, 2004)

\section{HASIL DAN PEMBAHASAN}

Hasil Tes Awal Kebugaran sebelum diberikan treatment dengan Latihan Tabata ditemukan yang memiliki kebugaran dengan skor sebagai berikut:

1) Skor 10-13 berada pada klasifikasi Kurang (K) sebanyak 14 orang.

2) Skor 14-17 kategori Sedang (S) sebanyak 8 orang.

3) Skor 18-21 berada kategori Baik (B) sebanyak 3 orang.

Hasil Tes Akhir kebugaran setelah diberikan treatment latihan tabata ditemukan yang memiliki kebugaran dengan skor sebagai berikut:

1) Skor 10-13 berada pada klasifikasi Kurang (K) sebanyak 2 orang.

2) Skor 14-17 berada pada kategori Sedang (S) sebanyak 8 orang.

3) skor 18-21 dikategorikan Baik (B) sebanyak 12 orang.

4) skor 22-25 pada kategorii Baik Sekali (BS) sebanyak 3 orang. 
Selanjutnya dilakukan uji Persyaratan Analisis. Untuk lebih jelasnya dapat dijelaskan pada diagram berikut:

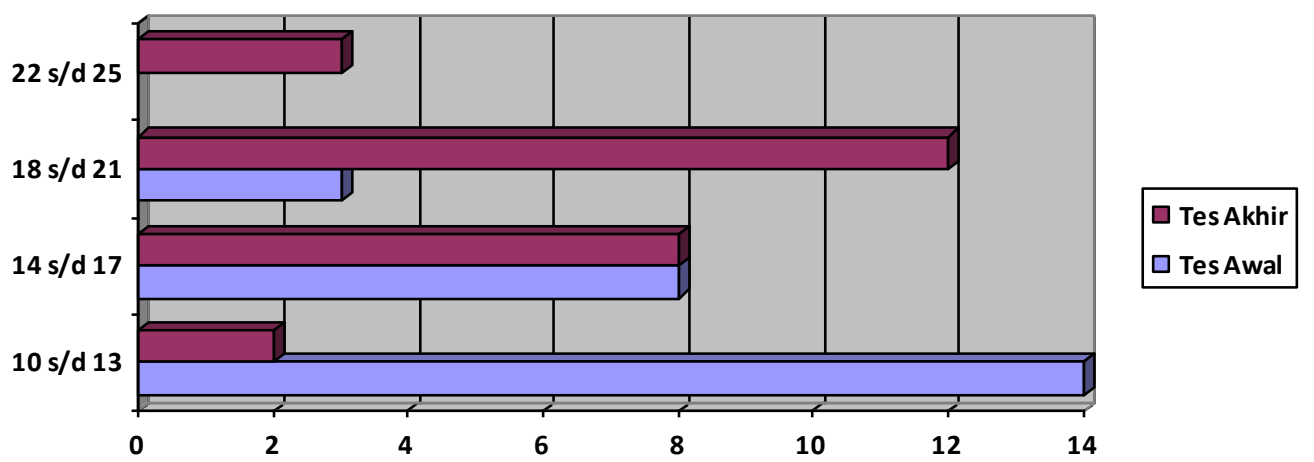

Gambar 1. Diagram Data

Distribusi hasil yang diperoleh dari uji normalitas menunjukkan hasilnya normal. karena masing-masing variabel probabilitasnya memenuhi kriteria $\left(\mathrm{L}_{\mathrm{o}}\right)<\left(\mathrm{L}_{\mathrm{t}}\right)$ seperti yang dijelaskan pada tabel berikut:

Tabel 4. Normalitas data

\begin{tabular}{ccccc}
\hline Data & $\boldsymbol{N}$ & $\boldsymbol{L o}$ & $\boldsymbol{L t}$ & Ket: \\
\hline $\begin{array}{c}\text { Tes } \\
\text { Awal }\end{array}$ & 25 & 0,085 & 0,173 & Normal \\
& & & & \\
\hline $\begin{array}{c}\text { Tes } \\
\text { Akhir }\end{array}$ & 25 & 0,036 & 0,173 & Normal \\
& & & & \\
\hline
\end{tabular}

Kemudian dilakukan uji homogenitas untuk mengetahui data dari varian yang sama atau tidak. Hasil pengujian datanya dapat ditunjukan dari tabel berikut ini:

Tabel 5. Rangkuman Hasil Pengujian Homogenitas

\begin{tabular}{ccc}
\hline $\boldsymbol{F h}$ & $\boldsymbol{F t}$ & Ket \\
\hline 1,47 & 3,38 & Homogen \\
\hline
\end{tabular}

Analisis diatas menunjukkan nilai $\mathrm{Fh}_{\mathrm{h}}=1,47$ sedangkan $\mathrm{F}_{\mathrm{t}}=3,38$ dengan memakai derajat kebebasan (n-1), serta taraf signifikansi probability pada $\alpha 0,05$. kesimpulannya data penelitian ini homogeny karena $1,47<3,38$. sehingga bisa dilanjutkan untuk pengujian hipotesis. 


\section{OLATRAGA}

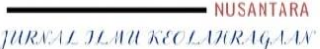

Jendral A. Yani Street Lorong Gotong Royong 9/10 Ulu

Palembang South Sumatera

Accredited

email jurnal: jurnalhon@univpgri-palembang.ac.id situs web: http://www.univpgri-palembang.ac.id

\section{Pengujian Hipotesis}

Hipotesis yang diuji tentang tabata workout dalam meningkatkan kebugaran, hasil perhitungan sebagai berikut :

Tabel 6. Hipotesis Data

\begin{tabular}{|c|c|c|c|c|c|c|}
\hline Latihan Tabata & Mean & thitung & A & ttabel & Hasil Uji & Keterangan \\
\hline Tes Awal & 14,05 & 4,52 & 0,05 & 1,711 & Signifikan & Ho ditolak \\
\hline Tes Akhir & 18,90 & & & & & Ha diterima \\
\hline
\end{tabular}

Dilihat dari perhitungan diatas, dapat dilihat nilai th $=4,52$ sedangkan nilai $\mathrm{t}_{\mathrm{t}}=1,711$ pada $\alpha 0,05$, derajat kebebasan $25(\mathrm{n}-1)$. karena $\mathrm{th}_{\mathrm{h}}>\mathrm{t}_{\mathrm{t}}$ dapat ditarik kesimpulan dari perbandingan tes awal dan tes akhir tersebut menunjukkan tabata workout memberikan pengaruh dalam meningkatkan Kebugaran Atlet Panahan UKM Umika.

\section{PEMBAHASAN}

Hipotesis yang diajukan ternyata sesuai dengan hasil pengujian yang dilakukan. Jadi, sudah jelas bahwasa tabata workout memberikan pengaruh dalam meningkatan kebugaran atlet. Latihan ini diberikan kepada Atlet UKM Panahan yang merupakan implementasi dari pemberian TKJI sesuai dengan klasifikasi tingkat usia.

Lebih lanjut "Kebugaran merupakan kepiawaian badan buat berperan secara efisien kala bekerja maupun melaksanakan kegiatan yang lain, serta masih mempunyai lumayan tenaga buat menanggulangi ataupun mengalami kondisi darurat yang bisa jadi muncul"(Palar et al., 2015). Kebugaran ini yang nantinya bisa dimanfaatkan untuk melatih kemampuan memanah secara maksimal.

"Seorang pemanah yang baik, wajib memahami metode dasar dengan baik. Metode dasar tersebut tidak cuma pada kemampuan metode tarikan busur, namun perlu mengaitkan aneka teknik yang sesuai dengan panahan"(Adhi Purnomo, 2014), lebih lanjut "Memanah dilakukan dengan peralatan anak panah, busur, target sebagai arah sasaran. Olahraga panahan ini memiliki keterampilan teknik dasar yang harus dikuasai diantaranya stand-nocking-extend-drawing- 
anchoring-aiming-follow through" (Arisman, 2019), kemudian sebagai penyempurnaan "berolahraga memanah ialah aktifitas yang membutuhkan kondisi fisik, psikologis serta keahlian lainnya"(Soegiyanto, 2011).

Setiap event olahraga panahan ini dilakukan dalam jangka waktu panjang bisa seharian dari pagi sampai sore hari tergantung nomor event yang diikuti. Jadi, diperlukan kebugaran fisik dari para atlet yang ingin bertanding. Untuk mendapatkan kebugaran yang bagus harus dilakukan melalui proses latihan. Untuk menunjang kebugaran bisa diberikan latihan tabata. "fittingness factor, lottery a bow without an arrow, lower-body burden breeding (low body-oriented circumference training), and upper-body burden breeding (shoulder, armrest and backoriented circumference training) were significant therein club"(Kim et al., 2015).

"Tabata merupakan sebuah metode yang melibatkan perbandingan latihan dengan waktu beristirahat selama pelaksananya (menggunakan interval higt intensity). Pelaksanaan latihan metode ini selama empat menit rinciannya (20 detik latihan dan 10 detik waktu istirahat) yang diberikan. Latihan ini menggunakan pola peningkatan power dalam mengubah arah secara cepat" (ROMDANI \& AGUS PRIANTO, 2018). Selanjutnya "Tabata merupakan jenis latihan HIIT yang digemari di seluruh dunia dan sudah dikembangkan. Tabata ini memiliki beban yang berat ditambah higt intensity pada setiap pos peserta yang berlatih. ini mampu meningkatkan dayatahan apabila dilakukan secara terusmenerus" (ADIL WIJAYA \& SYAFII, 2018).

Jadi, latihan tabata merupakan latihan yang mampu meningkatkan perubahan komponen fisik menjadi lebih baik. Hal ini juga dibuktikan dari hasil peningkatan kebugaran yang dialami oleh Atlet UKM Panahan Umika.

\section{KESIMPULAN}

Latihan tabata ternyata efektif dalam meningkatkan Kebugaran Atlet UKM Panahan dengan hasil uji hipotesis didapat th besar dari t (thitung diperoleh 4,52 dari tabel diperoleh 1,711) Maka latihan ini cukup tepat dijadikan sebagai penunjang untuk meningkatkan kebugaran Atlet UKM Panahan. 


\section{OLAHRAGA}

Jendral A. Yani Street Lorong Gotong Royong 9/10 Ulu Palembang South Sumatera

\section{Saran}

Penelitian ini masih perlu dikembangkan lagi dan masih belum sempurna. maka, untuk peneliti selanjutnya agar lebih bisa mengembangkan lagi ke arah yang lebih baik seperti penambahan jumlah sampel, intrument tes yang digunakan, sarana prasarana yang lebih lengkap maupun mencari bentuk latihan lain yang lebih pas dijadikan acuan dalam meningkatkan kebugaran yang lebih baik.

\section{DAFTAR PUSTAKA}

Adhi Purnomo. (2014). Model Pengembangan Pemanduan Bakat Olahraga Panahan Pegawai Tetap Pada Kementrian Pemuda Dan Olahraga Republik Indonesia. Journal of Physical Education Health and Sport, 1(1), 28-34. https://doi.org/10.15294/jpehs.v1i1.3009

ADIL WIJAYA, M., \& SYAFII, I. (2018). Pengaruh Latihan Tabata Terhadap Peningkatan Vo2 Max Pada Academy Abyasa U-16 Kab. Nganjuk. Jurnal Prestasi Olahraga, 1(1), 1-7.

Arifin, Z. (2018). Pengaruh Latihan Senam Kebugaran Jasmani (Skj) Terhadaptingkat Kebugaran Siswa Kelas V Di Min Donomulyo Kabupaten Malang. Journal AL-MUDARRIS, 1(1), 22. https://doi.org/10.32478/almudarris.v1i1.96

Arisman, A. (2019). PENGARUH METODE RANGKAIAN BERMAIN TERHADAP KETERAMPILAN DASAR OLAHRAGA PANAHAN SISWA EKTRAKULIKULER SIT (SEKOLAH ISLAM TERPADU) AULADI PALEMBANG. Halaman Olahraga Nusantara (Jurnal Ilmu Keolahragaan). https://doi.org/10.31851/hon.v2i1.2460

ARISMAN, A., \& Okilanda, A. (2020). Pengembangan Diri Melalui Olahraga Panahan. Jurnal MensSana. https://doi.org/10.24036/jm.v5i1.138

Arikunto, Suharsimi. (2006). Prosedur Penelitian Suatu Pendekatan Praktik. Jakarta: PT. Rineka Cipta

Arsil. (2015). Evaluasi Pendidikan Jasmani dan Olahraga. Padang: Wineka Media

Devy Amelia Nurul Alamsyah*,Retno Hestiningsih, L. D. S. (2017). FaktorFaktor Yang Berhubungan Dengan Kebugaran Jasmani Pada Remaja Siswa Kelas Xi Smk Negeri 11 Semarang. Jurnal Kesehatan Masyarakat (eJournal), 5(3), 77-86.

Iqbal, Hasan. (2004). Analisis data penelitian dengan statistic. Jakarta: PT. Bumi Aksara

Kim, H. B., Kim, S. H., \& So, W. Y. (2015). The relative importance of performance factors in Korean archery. Journal of Strength and Conditioning Research. https://doi.org/10.1519/JSC.0000000000000687

Palar, C. M., Wongkar, D., \& Ticoalu, S. H. R. (2015). MANFAAT LATIHAN OLAHRAGA AEROBIK TERHADAP KEBUGARAN FISIK MANUSIA. Jurnal E-Biomedik. https://doi.org/10.35790/ebm.3.1.2015.7127 
ROMDANI, S., \& AGUS PRIANTO, D. (2018). Pengaruh Latihan Latihan Tabata Circuit Training Terhadap Peningkatan Kelincahan Pada Pemain Futsal. Jurnal Prestasi Olahraga, 1(4), 1-5.

Soegiyanto. (2011). Kondisi Atlet Panahan Program Atlet Andalan Nasional Indonesia Emas (Prima). Media Ilmu Keolahragaan Indonesia. https://doi.org/10.15294/miki.vli1.1132

Sugiyono. (2010). Metode Penelitian Pendidikan. Bandung: Alfabeta.

Wiarto, Giri. (2015). Panduan Berolahraga Untuk Kesehatan dan Kebugaran. Yogyakarta: Graha Ilmu 